\title{
Comparison of the Recycling Efficiency of Metakaolin and Laboratory-Synthesized Zeolite Types LTA and LSX on Used Lubricant Engine Oil
}

\author{
Bright Kwakye-Awuah ${ }^{1}$, Ralph Kwakye, Baah Sefa-Ntiri ${ }^{2}$, Isaac Nkrumah ${ }^{1}$, \\ Elizabeth Von-Kiti ${ }^{1} \&$ Craig Williams ${ }^{3}$ \\ ${ }^{1}$ Kwame Nkrumah University of Science and Technology, Department of Physics, UPO, PMB, Kumasi \\ ${ }^{2}$ Department of Physics, University of Cape Coast, PMB, Cape Coast \\ ${ }^{3}$ Faculty of Science and Engineering, University of Wolverhampton, Wolverhampton, United Kingdom \\ Correspondence: Bright Kwakye-Awuah, Kwame Nkrumah University of Science and Technology, Department \\ of Physics, UPO, PMB, Kumasi. E-mail: bkwakye-awuah.cos@knust.edu.gh
}

Received: March 2, 2018

Accepted: May 24, 2018

Online Published: July 12, 2018

doi:10.5539/apr.v10n4p11

URL: https://doi.org/10.5539/apr.v10n4p11

\begin{abstract}
Zeolite types LTZ and LSX were synthesized from bauxite and kaolin in Ghana and characterized by x-ray diffraction, scanning electron microscopy, energy dispersive $\mathrm{x}$-ray spectroscopy and Fouries transformed infrared spectroscopy. The zeolites were then applied to used lubricant oil and parameters lubricant engine oil were measured and compared to those of fresh ones. Parameters such as flashpoint, viscosity index, pour point, sulfur content, heavy metals, specific gravity, refractive index and carbon residue were analyzed. The results obtained showed that zeolite types A and X successfully removed heavy metals, particularly lead, copper and iron that were in the spent oil. A removal efficiency of $23.40 \% \mathrm{Fe}, 96.76 \% \mathrm{Zn}, 19.05 \% \mathrm{Cu}$ and $12 \% \mathrm{Cr}$ were obtained for Zeolite A with a yield of $62 \%$ whilst $32.81 \% \mathrm{Fe}, 39.00 \%$, Zn, $47.61 \%$, Cu and $24 \% \mathrm{Cr}$ were obtained for zeolite LSX with a yield of $67 \%$. The viscosity index of the virgin, zeolite LTA treated and zeolite LSX treated oils were 115,121 and 115 respectively. These results showed that used engine oils recovered using glacial acetic acid and zeolites A and LSX can be reused.
\end{abstract}

Keywords: Zeolite LTA, zeolite LSX, used oil, recycling, efficiency

\section{Introduction}

Spent lubricants or used oils are lubricating oils that have lost their greasing properties as a result of worn out of their additives (Hamawand, Yusaf, \& Rafat, 2013). The increase in the number of vehicles has led to an increase in the yearly volume consumption of lubricating engine oils. This has eventually, led to an increase in the number of fresh and waste lubricating engine oils being produced annually. Used or spent oil is normally contaminated with salt, water, broken down additive components heavy metals ions, gum, varnish and other materials. Only small volumes of these used oils generated are normally processed but huge quantities of these oils are used in ways which are harmful to the environment (Hamawand et al., 2013; Kajdas, 2000).

The practices involved in the disposal of spent oils are by throwing them into landfills, gutters, running waters and ground which at the end do not safeguard the environment nor conserve its value resource (Kajdas, 2000). Spent or used oils are used for wood preservation, greasing, pouring them into pit latrines, gutters and running waters. These pollutants may find their way into running water bodies or penetrate the ground and cause serious destruction to aquatic life or may cause ground water contamination (Boughton \& Horvath, 2004). Another method employed by most people in disposing spent lubricating oils is burning. These oils are sometimes burnt in incinerators and kilns. However, this method results in the production of carcinogens and ash which creates a lot of problems in the environment such as air pollution (Boughton \& Horvath, 2004; Whisman, Reynolds, Goetzinger, Cotton, \& Brinkman, 1978). Recycling of the spent lubricating oils provide efficient way of reducing the environmental pollution problems associated with their disposal whilst at the same time adding value to the spent lubricant which is considered waste (Rincon, Canizares, \& Garcia, 2005; Reis \& Jeronimo, 1988; Whisman et al., 1978; Quang, Carriero, Schieppati, Comte, \& Andrews, 1974). 
The conventional methods of recycling of waste engine oil either requires a high cost technology such as vacuum distillation or the use of toxic materials such as sulfuric acid. Over the years acid-clay has been used as a recycling method but was found to have many disadvantages aside not being able treat multigrade oil and also not efficient in removing asphaltic impurities (Fox, 2007). Solvent extraction which involves selective dissolution of undesirable aromatic component leaving desirable saturated components such as alkanes in order to improveoxidative stability and viscosity characteristics of the base oil replaced acid treatment as the method. However, this method was found to be extremely expensive (Shakirullah et al., 2006; Canizares, \& Garcia, 2005; Rincon, Canizares, \& Garcia, 2003; Martins, 1997). In recent years propane with characteristic solubility in paraffinic, waxy and oxygenated materials and insoluble in asphaltenes has been used as a solvent (Dang, 1997). The shortfall of this method is the hazardous and flammable nature of propane, losses in solvent extracted and highly skilled and mainetenace cost of the the process. In addition, extraction occurs at pressures higher than 10 atm and requires high pressure sealing systems which makes solvent extraction plants expensive to construct, operate and the method also produces remarkable amounts of hazardous by-products (Kajdas, 2000). Membrane technology is another method that has been used for the regeneration of used lubricating oils. In this method three types of polymer hollow fiber membranes [polyethersulphone (PES), polyvinylidene fluoride (PVDF), and polyacrylonitrile (PAN)] were used for recycling the used engine oils. The process being a continuous one is carried out at $40{ }^{\circ} \mathrm{C}$ and $0.1 \mathrm{MPa}$ pressure and it aims at removing metal particles and dusts from used engine oil and also improves the recovered oils liquidity and flash point. Despite the above mentioned advantages, the main drawback is the expensive membranes which may get damaged and fouled by large particles (Puerto-Ferre, \& Kajdas, 1994). Vacuum distillation and hydrogenation are two other methods that have been employed for recycling of used engine oil (Kwakye-Awuah, Von-Kiti, Nkrumah, Ikyereve, \& Williams, 2016). This method removes most of the contaminants from the waste oil. The advantages of these process are the high quality standard as well as minimized by-products. However, this method involves very high investment cost (Kwakye-Awuah, Von-Kiti, Buamah, Nkrumah, \& Williams, 2014; Kwakye-Awuah, Von-Kiti, Nkrumah, \& Williams, 2013).

Removal of the degraded additives and contaminants in the spent lubricating oil by using acetic acid - zeolites can help in restoring the properties of the oil as well as minimizing cost and waste by-products as well as enhancing product yield. In this work two types of synthetic zeolites: zeolite types A (LTA) and low silica type X (LSX) were synthesized from kaolin and bauxite as described in our earlier report (Kwakye-Awuah et al., 2014). These two zeolites were chosen based on their pore sizes and crystal morphology which makes them highly efficient in their adsorption and ion exchange properties: two properties required for efficient regeneration of spent engine oil.

\section{Method}

\subsection{Materials and Reagents}

Natural raw materials: bauxite and kaolin were sampled from Ghana Bauxite Mining Company site, at Awaso in the Western Region of Ghana. Sodium hydroxide (Analar grade) was purchased from Analar Normapur, UK and distilled water was obtained from the Water Research laboratory, KNUST. Bauxite was sampled from Awaso in the Western Region particularly close to the Ghana Bauxite Company site. The kaolin and bauxite were grounded and sieved with $0.75 \mu \mathrm{m}$ mesh sieve under dry conditions. Virgin lubricant engine oil were purchased from Ghana Oil (Goil) filling station in Kwahu. Spent lubricant engine oil were collected from mechanical shop in Kwahu at least 3 months after being used in vehecles by commercial drivers.

\subsection{Synthesis of Zeolites LTA and LSX}

\subsubsection{Synthesis of Zeolite LTA}

Starting with zeolite LSA the method, the aluminosilicate source (kaolin) was sieved under dry conditions with a size fraction of 200 mesh to select particles of size $<75 \mu \mathrm{m}$ for zeolite synthesis. The dried powder was then calcined at a temperature of $600{ }^{\circ} \mathrm{C}$ to form metakaolin. Meanwhile, $7.5 \mathrm{~g}$ of $\mathrm{NaOH}$ pellets were pounded into a fine powder at room temperature and dry-mized with $5.0 \mathrm{~g}$ of the metakaolin for $30 \mathrm{~min}$ to obtain a homogenous mixture. The resultant mixture was fused at a temperature of $600{ }^{\circ} \mathrm{C}$ for 1 hour. The fused product was grounded in a mortar into a fine powder of which $10.00 \mathrm{~g}$ was then added to in $100 \mathrm{ml}$ of distilled water under magnetic stirring conditions to form reaction gel/slurry with a specific molar composition. The mixed gels were then transferred into polytetrafluoroethylene (PTFE) Teflon bottles (Cowie Technology Ltd) and heated in an oven at $100{ }^{\circ} \mathrm{C}$ for 6 hours, removed from the oven at the scheduled time and quenched in cold water. The crystallized ssample was filtered and the mother liquor was kept in a diiferent beaker. The sample was then washed copiuously with distilled water until the $\mathrm{pH}$ of the filtrate was 10 . Finally, the samples were oven dried overnight at $100{ }^{\circ} \mathrm{C}$ grounded into fine powder, weighed and kept in plastic bags in a cool cupboard. 


\subsubsection{Synthesis of Zeolite LSX}

Zeolite LSX was synthesized following our earlier synthesis protocol Kwakye-Awuah et al. (2014). Aluminate solution was extracted from bauxite by digesting $4 \mathrm{M}$ sodium hydroxide in a slurry of bauxite at $130^{\circ} \mathrm{C}$ for 5 hours and. $50 \mathrm{ml}$ portion of the aluminate extract was added to $100 \mathrm{ml}$ the mother liquor obtained after crystallization step in the synthesis of zeolite LTA to form reaction gel with a specific molar composition. The hydro-gel was aged for 24 hours at room temperature, transferred into polytetrafluoroethylene (PTFE) Teflon bottles (Cowie Technology Ltd) and heated in an oven at $100{ }^{\circ} \mathrm{C}$ for 4 hours to obtain crystallized sample. The crystallized ssample was filtered and the mother liquor was kept in a diiferent beaker. The sample was then washed copiuously with distilled water until the $\mathrm{pH}$ of the filtrate was 10 . Finally, the samples were oven dried overnight at $100{ }^{\circ} \mathrm{C}$ grounded into fine powder, weighed and kept in plastic bags in a cool cupboard.

\subsection{Characterization of Synthesized Zeolites}

A PANalytical Empyrean Powder X-ray diffractometer (PANalytical, UK) was used to collect data using BraggBrentano geometry and a slit configuration of a degree fixed divergence slit of $0.25^{\circ}$.

The morphology of the starting materials and the as-synthesized zeolites were determined by a Zeiss EVO 500 (Zeiss, UK) scanning electron microscope (SEM) equipped with energy dispersive x-ray spectrometer (Zeiss, UK). Surface morphology and atomic percentage compositions for the present study were done using EDX. The samples were prepared similarly to SEM for EDX analysis. The vibrational properties as well as the chemical bonds present in the samples were analyzed with a Mattson FTIR spectrometer (Mattson Instruments, UK) equipped with a ZnSe crystal plate attached to the spectrometer with a mercury cadmium telluride. The thermal analysis were conducted with a thermogravimetric analyzer equipped with differential thermal analysis software (TGA-DTA)

\subsection{Purification of Used Engine Oil}

Samples of the used oil from commercial vehecles which had been used for close to four months were collected and filtered to remove impurities such as sand, metal chips and micro impurities by using a vacuum pump, Buchner funnel, and a filter paper. Three litres of the spent oil were filtered for the sample preparation and allowed to settle for twelve hours. Further filtration was done by centrifugation for 20 minutes at $10000 \mathrm{rpm}$ causing the suspended particles in the oil to settle at the bottom of the flask, and the liquid portion was decanted. The decanted liquid was preheated and $100 \mathrm{ml}$ of it was poured into a beaker and treated with $10 \mathrm{ml}$ of $99.9 \%$ glacial acetic acid. The mixture was thoroughly mixed at a temperature of $50^{\circ} \mathrm{C}$ to obtain a homogenized acid-oil mixture; allowed to cool and kept for 24 hours. The acid-oil mixture was poured into a separating funnel and the acid sludge was discharged at the bottom of the separating funnel and was removed gradually and repeatedly. 5, 10, 15 and $20 \mathrm{~g}$ of Zeolite LTA and Zeolite LSX were each mixed with $100 \mathrm{ml}$ of the acid treated oil. The mixture was well stirred on a hot plate magnetic stirrer for 20 minutes and then centrifuged. The refined lube oils were then analyzed.

\subsection{Quality Control Tests}

Three groups of oil (virgin and used) were performed: 1. Analysis of oil physical and chemical properties including tests such as: Flash Points by Cleveland Open Cup Tester ASTM D 92 (ASTM, 2004), Pour Point ASTM D 97 (ASTM, 2004), Viscosity Index ASTM D 2270 (ASTM, 2004), Water and Sediment ASTM D 4007 (ASTM, 2004), Rams bottom Carbon Residue ASTM D 524 (ASTM, 2004), Total acid number (TAN) ASTM D 664 (ASTM, 2004), Refractive Index ASTM D 1218 (ASTM, 2004), and Density (Specific Gravity) ASTM D 1298 (ASTM, 2004). 2. Analysis of metallic contained by atomic absorption spectrometer (AAS) and 3. Analysis of oxidative components by a Fourier Transform Infrared Spectrometer. 


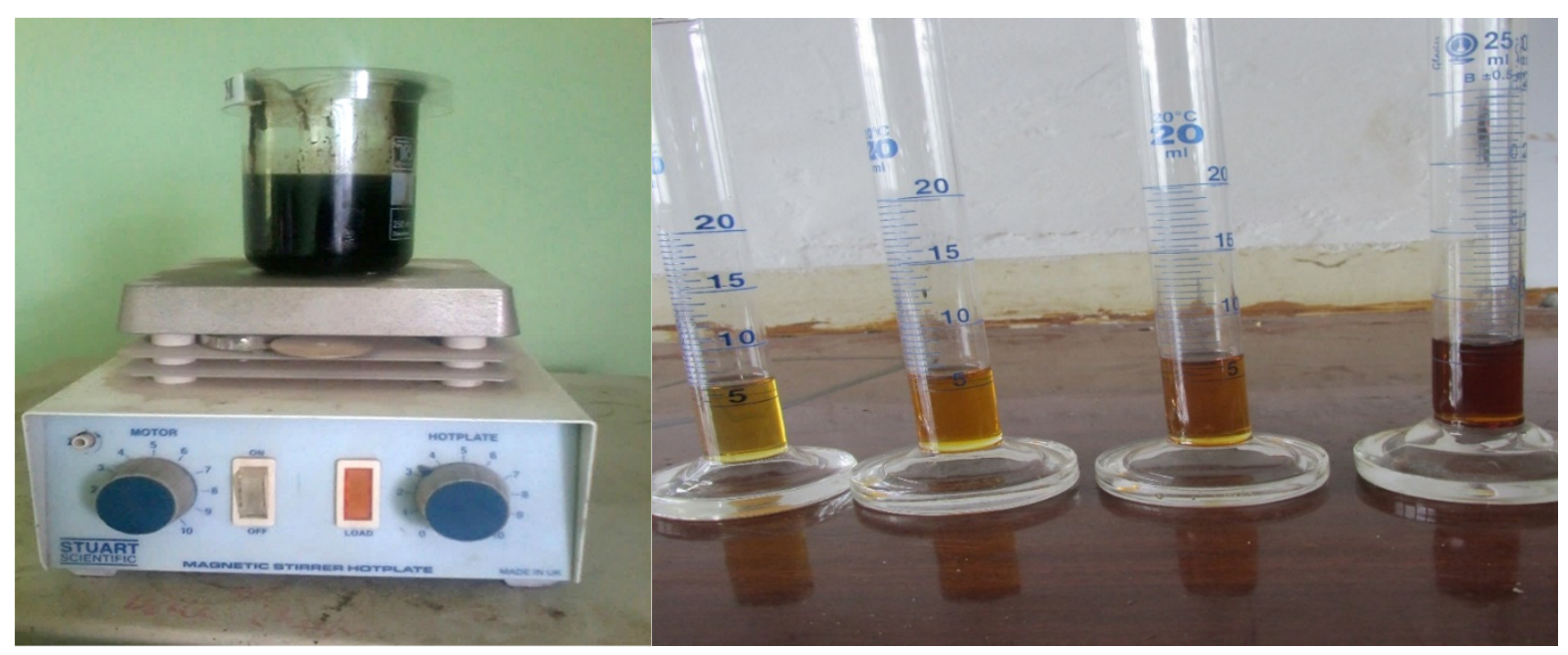

Figure 1. Sample of used and treated engine oils

\section{Results and Discussion}

\subsection{Characterization of Zeolites LTA and LSX}
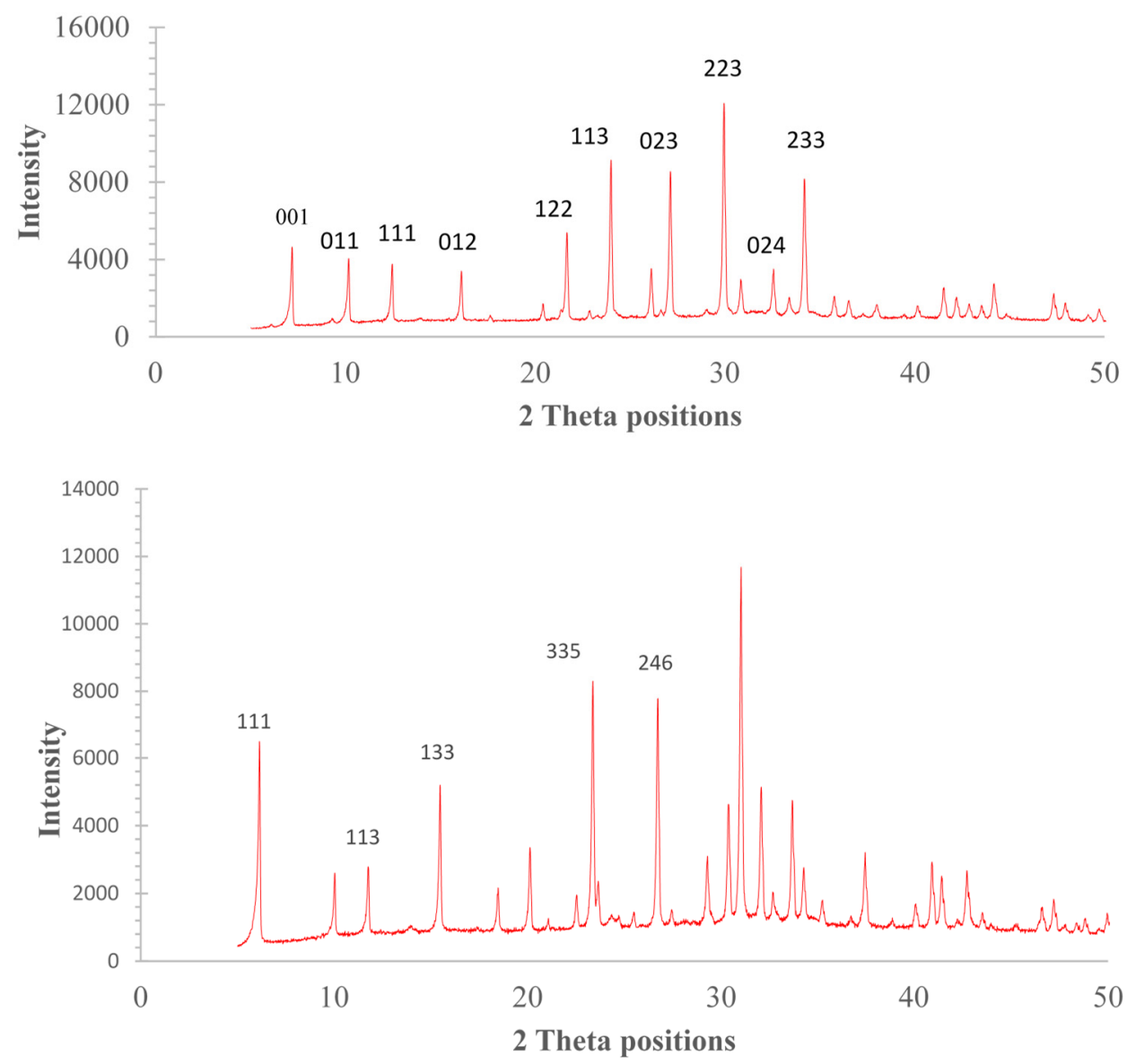

Figure 2. X-ray diffractograph of top: zeolite LTA and bottom: zeolite LSX 
From the XRD spectra the positions of the peaks in the sample were at $2 \theta=6.15,11.74,15.47,23.34$ and $26.75^{\circ}$. These peaks coreespond well with that of zeolite LSX synthesized from chemical reagents in the ICDD database. In addition the SEM images (Figure 3) as well as the EDX spectra (Figure 4 and and Table 1) confirmed the cubic and spherical shapes of zeolite LTA and LSX.

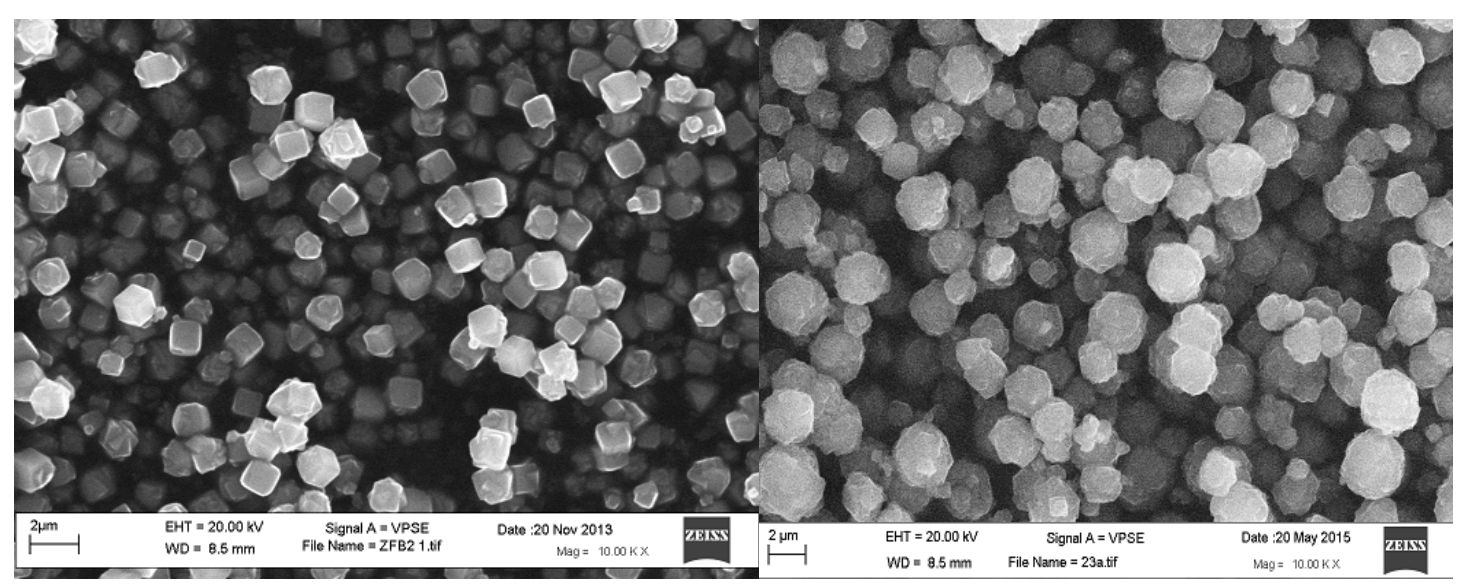

Figure 3. Scanning electron micrograph of left: zeolite LTA and rght: zeolite LSX

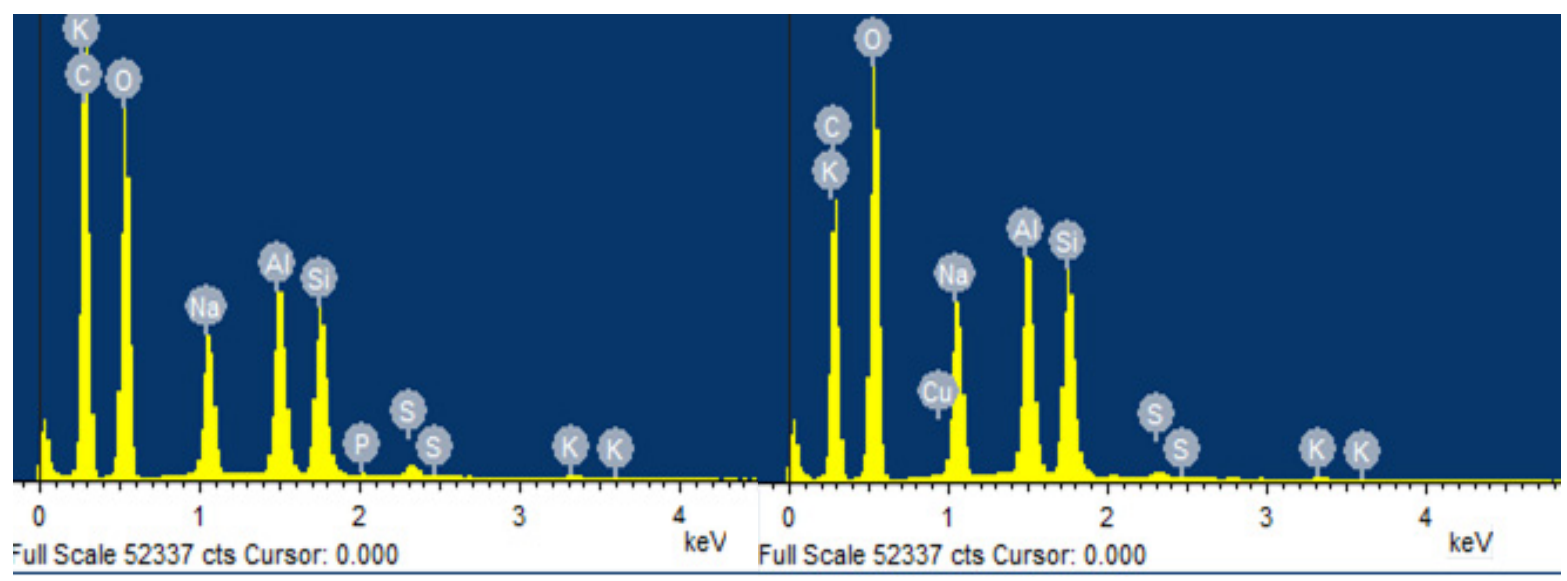

Figure 4. Energy dispersive x-ray spextrum of left: zeolite LTA and rght: zeolite LSX

Table 1. Composition of zeolite LSX as determined by energy dispersive $\mathrm{x}$-ray analysis

\begin{tabular}{ccc}
\hline Element & Weight Zeolite LTA (\%) & Weight Zeolite LSX (\%) \\
\hline $\mathrm{SiO}_{2}$ & 46.44 & 46.65 \\
$\mathrm{Na}_{2} \mathrm{O}$ & 6.55 & 5.59 \\
$\mathrm{Al}_{2} \mathrm{O}_{3}$ & 45.85 & 46.72 \\
$\mathrm{~K}_{2} \mathrm{O}_{3}$ & 1.06 & 0.95 \\
$\mathrm{LOI}$ & 0.10 & 0.09 \\
Totals & $\mathbf{1 0 0 . 0 0}$ & $\mathbf{1 0 0 . 0 0}$ \\
\hline
\end{tabular}




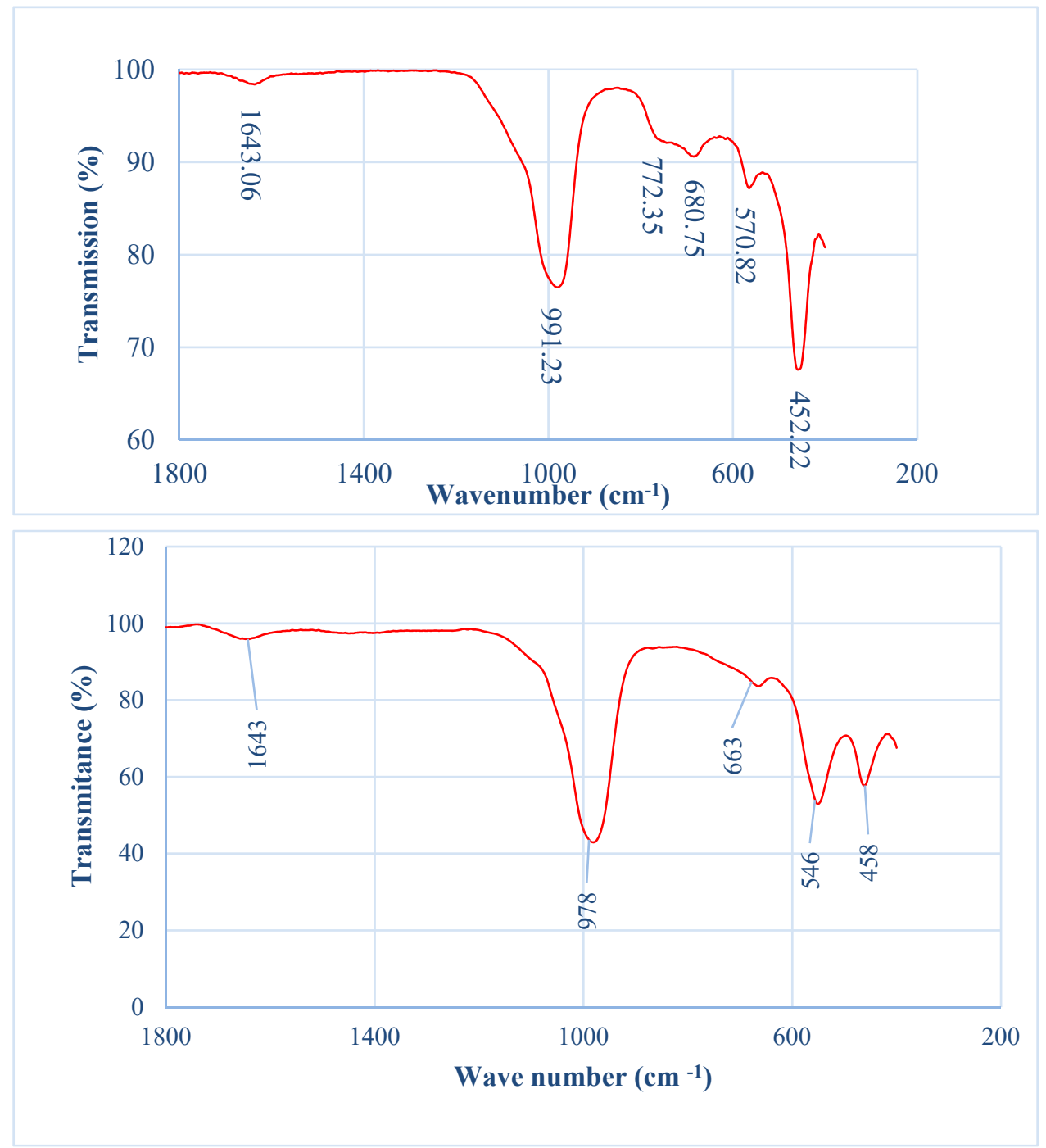

Figure 5. Fourier transformed infrared spectra of top: zeolite LTA and down: zeolite LSX

FTIR spectra for zeolite LTA and LSX are presented in Figure 5. The band of transmittance frequency of 991.23 $\mathrm{cm}^{-1}$ corresponding to an internal tetrahedron asymmetrical stretch vibration was found in the zeolite. The band at $680.57 \mathrm{~cm}^{-1}$ correspond to linkage due to symmetric stretch was also found whilst the band at $570.82 \mathrm{~cm}^{-1}$ relates to the existence of double ring in the framework structure of zeolites was also present (Kwakye-Awuah et al., 2014). These bands suggest that the synthesized sample was zeolite in the class of zeolite LTAA, due to auspicious double ring vibrational peaks. For zeolite LSX, the band at $1047 \mathrm{~cm}^{-1}$ was shifted to lower frequency bands at 978 $\mathrm{cm}^{-1}$. The band at $800 \mathrm{~cm}^{-1}$ disappeared in the zeolite products. The low intensity bands at 635 and $565 \mathrm{~cm}^{-1}$ were shifted to higher bands at $663 \mathrm{~cm}^{-1}$ and lower at frequency band $546 \mathrm{~cm}^{-1}$ respectively. The band at $424 \mathrm{~cm}^{-1}$ was also shifted to higher frequency bands at $458 \mathrm{~cm}^{-1}$. The typical bands of zeolite-LSX representing the asymmetric Al-O $\left(973-980 \mathrm{~cm}^{-1}\right)$ and symmetric Al-O $\left(673-690 \mathrm{~cm}^{-1}\right)$ stretches, double rings $\left(530-538 \mathrm{~cm}^{-1}\right)$ in the framework structures of the zeolite materials were observed and they showed a constant intensity (Kwakye-Awuah et al., 2014). 


\subsection{Characterization of Spent and Zeolite-Treated Spent Engine Oil}

\subsubsection{Physical Properties}

Table 2. Summary of the physical properties of engine oil samples with their various treatment methods

\begin{tabular}{|c|c|c|c|c|c|c|c|c|}
\hline No. & Sample & $\begin{array}{c}\text { Flash } \\
\text { Point } \\
\left({ }^{\circ} \mathrm{C}\right)\end{array}$ & $\begin{array}{c}\text { Pour } \\
\text { Point } \\
\left({ }^{\circ} \mathrm{C}\right)\end{array}$ & $\begin{array}{c}\text { Kinematic } \\
\text { Viscosity @40 } \\
{ }^{\circ} \mathrm{C}\end{array}$ & $\begin{array}{c}\text { Kinematic } \\
\text { Viscosity@100 } \\
{ }^{\circ} \mathrm{C}\end{array}$ & $\begin{array}{l}\text { Viscosity } \\
\text { Index }\end{array}$ & $\begin{array}{l}\text { Refractive } \\
\text { index }\end{array}$ & $\begin{array}{l}\text { Specific } \\
\text { Gravity }\end{array}$ \\
\hline 1 & Virgin engine oil & 264 & -19 & 149.91 & 16.30 & 115 & 1.493 & 0.697 \\
\hline 2 & Used engine oil & 232 & -18 & 169.00 & 15.80 & 94 & 1.591 & 0.831 \\
\hline 3 & $\begin{array}{l}\text { Recycled engine oil by acetic acid- } \\
\text { metakaolin }\end{array}$ & 232 & -15 & 129.20 & 15.10 & 118 & 1.413 & 0.873 \\
\hline 4 & $\begin{array}{l}\text { Recycled engine oil by acetic acid- } \\
\text { zeolite LTA }\end{array}$ & 121 & -17 & 134.60 & 15.70 & 121 & 1.465 & 0.663 \\
\hline 5 & $\begin{array}{l}\text { Recycled engine oil by acetic acid- } \\
\text { zeoliteLSX }\end{array}$ & 168 & -19 & 136.90 & 15.40 & 115 & 1.472 & 0.691 \\
\hline
\end{tabular}

The flash points of the recycled spent oils were determined and the values compared with that of the virgin oil and used oil. An engine oil's flash point is the most reduced temperature at which the oil when heated under determined conditions radiates adequate vapour. When this vapour blends with air, it can be ignited suddenly by a predetermined fire. It is a measure of how the oil is tainting. A low flash point indicate tainting with volatile species such as gasoline. From Table 2, the samples treated with Zeolites LTA and LSX had lowest averaged flash points as compared to that of kaolin, spent oil and the virgin oil although the values were in acceptable regions. The high flash point of the virgin oil $\left(264^{\circ} \mathrm{C}\right)$ was due to the presence of sdditives. The decreased values of the flash points for the spent and those treated with both zeolites LTA and LSX were due to fuel contamination and the addition of glacial acetic acid, which reacted with the additives in the oil (Hamawand et al., 2013). Furthermore, the bronsted and Lewis acid sites in the zeolites are likely to have also reacted with the additives causing the marked reduction in the flash point although the values were well within the minimum $\left(55^{\circ} \mathrm{C}\right)$ flash point temperature. Similar explanation could be attributed to other properties such as viscosity, refractive index and specific gravity of the oil.

The ideal pour point temperature for engine oil is about $15^{\circ} \mathrm{C}$. Reacting the spent lubricating oil with glacial acetic acid and later treating the solvent extracted with kaolin gave remarkable results of $-15^{\circ} \mathrm{C}$. This was higher than that of the virgin oil. It is very probable that the additives in the virgin oil may have affected its pour point. This was not the case however in the used oil and both the zeolites treated oils because the additives had little effect on their pour points.

The Kinematic viscosity at $40{ }^{\circ} \mathrm{C}$ of the recovered used oil was affected by the metakaolin reducing it from 169.9 cSt to $129.2 \mathrm{cSt}$ and that of zeolites A and LSX were reduced to $134.6 \mathrm{cSt}$ and $136.9 \mathrm{cSt}$ respectively. Comparing these values to the virgin oil, the average kinematic viscosity recorded at $40{ }^{\circ} \mathrm{C}$ was $149.91 \mathrm{cSt}$. At $100{ }^{\circ} \mathrm{C}$ the average viscosity values for all the recycled oil samples differs slightly from that of the used oil. The spent lubricant had its original kinematic viscosity at $100{ }^{\circ} \mathrm{C}$ increased by $13 \%$ compared to the virgin oil. However, the kinematic viscosity of the spent lubricant was not greatly affected at $40{ }^{\circ} \mathrm{C}$. It would appear that recycling the spent lubricating oil with metakaolin, zeolites A and LSX gave very comparable results at both temperatures $\left(40^{\circ} \mathrm{C}\right.$ and $\left.100{ }^{\circ} \mathrm{C}\right)$ as compared to that of the virgin oil. The results from all the adsorbents showed a reduction in the kinematic viscosity of the spent oil respectively. This meant that all the adsorbents were effective in removing the oxidized products, deposits, and varnishes from the spent oil (Diaz, Bernardo, Fernandez, \& Folgueras, 1996). This was also an indication of the removal of some of the additives which had been originally added to the lubricating oil in enhancing its viscosity.

The average viscosity index of the recycled used oil with metakaolin was 118, higher than that of the used oil which was 94. Viscosity index of the zeolites LTA had an average value of 121 and that of zeolite LSX was 115. Zeolite LTA had the highest viscosity index compared to the virgin oil and the spent oil. The viscosity index of all the recycled oils had better values than even the virgin oil. Clearly all the adsorbents had a very good effect on the viscosity index of the recycled oil. The viscosity index of all the recycled oils were high. Hence, there is no need to add additives to improve same. 


\subsubsection{Chemical Properties}

The used oil was found to have an average acid number of $10.2138 \mathrm{mgKOH} / \mathrm{g}$ (Table 3). After recycling the recovered used oil with metakaolin this dropped to an average value of $4.2045 \mathrm{mgKOH} / \mathrm{g}$. However, the addition of zeolites (LTA and LSX) to the recovered used oil dropped to $3.0401 \mathrm{mgKOH} / \mathrm{g}$ for zeolite LTA but increased slightly to $4.2422 \mathrm{mgKOH} / \mathrm{g}$ for zeolite LSX. The virgin oil had an average acid number $5.1885 \mathrm{mgKOH} / \mathrm{g}$. These results showed that the organic and inorganic acids, esters phenolic compounds water and corrosive materials which resulted from oxidation process occurring in the engine at high temperatures have been successfully reduced.

Zinc are added to engine oil as zinc diethyldithiophosphate (ZDDP), zinc dithiophosphates, and zinc dialkyldithiocarbamates. Average zinc concentration in the virgin oil was $0.0527 \mathrm{ppm}$. This was added to the base oil as part of multi-functional additives for improving oil's performance. Other metals also found in the virgin oil were Iron with an average concentration of $0.0057 \mathrm{ppm}$, copper with an average concentration of $0.0013 \mathrm{ppm}$ and Chromium with an average concentration of $0.0047 \mathrm{ppm}$.

Table 3. Summary of the chemical properties of engine oil samples with their various treatment methods

\begin{tabular}{|c|c|c|c|c|c|}
\hline No. & Sample & $\begin{array}{c}\text { Total Acid No } \\
\mathrm{mgKOH} / \mathrm{g}\end{array}$ & $\begin{array}{c}\text { Metallic content } \\
(\mathrm{ppm})\end{array}$ & $\begin{array}{c}\text { Sulphur content } \\
(\%)\end{array}$ & $\begin{array}{c}\text { Carbon residue } \\
(\%)\end{array}$ \\
\hline 1 & Virgin engine oil & 5.186 & $\begin{array}{l}\mathrm{Fe}^{2+}: 0.0057 \\
\mathrm{Zn}^{2+}: 0.0527 \\
\mathrm{Cu}^{2+}: 0.0013 \\
\mathrm{Cr}^{2+}: 0.0047\end{array}$ & - & 0.55 \\
\hline 2 & Used engine oil & 10.214 & $\begin{array}{c}\mathrm{Fe}^{2+}: 0.064 \\
\mathrm{Zn}^{2+}: 0.056 \\
\mathrm{Cu}^{2+}: 0.0021 \\
\mathrm{Cr}^{2+}: 0.0050\end{array}$ & 0.9 & 1.82 \\
\hline 3 & $\begin{array}{l}\text { Recycled engine oil by acetic acid- } \\
\text { metakaolin }\end{array}$ & 4.205 & $\begin{array}{l}\mathrm{Fe}^{2+}: 0.0082 \\
\mathrm{Zn}^{2+}: 0.0028 \\
\mathrm{Cu}^{2+}: 0.0013 \\
\mathrm{Cr}^{2+}: 0.0067\end{array}$ & $<0.01$ & 0.73 \\
\hline 4 & $\begin{array}{l}\text { Recycled engine oil by acetic acid- } \\
\text { zeolite LTA }\end{array}$ & 3.040 & $\begin{array}{l}\mathrm{Fe}^{2+}: 0.0049 \\
\mathrm{Zn}^{2+}: 0.0018 \\
\mathrm{Cu}^{2+}: 0.0017 \\
\mathrm{Cr}^{2+}: 0.0044\end{array}$ & $<0.01$ & 0.63 \\
\hline 5 & $\begin{array}{l}\text { Recycled engine oil by acetic acid- } \\
\text { zeoliteLSX }\end{array}$ & 4.242 & $\begin{array}{l}\mathrm{Fe}^{2+}: 0.0043 \\
\mathrm{Zn}^{2+}: 0.0034 \\
\mathrm{Cu}^{2+}: 0.0011 \\
\mathrm{Cr}^{2+}: 0.0038\end{array}$ & $<0.01$ & 0.61 \\
\hline
\end{tabular}

The recycling of the used oil with metakaolin and the zeolites as compared to that of the used oil led to a reduction in zinc content by $94.96 \%, 96.76 \%$ for zeolite LTA and $93.88 \%$ for zeolite LSX figure. The wearing of the galvanized piping in an engine block led to an upsurge in the average concentration of metals in the used engine oil. A very common wear metal in a car's engine block introduced into a lubrication oil after a period of use was iron. Iron has been reported to emanate from various places in an engine block such as pistons, camshafts and crank shaft, liners, rings, gears, and the oil pump (T. Yusaf, B. F. Yusaf, \& Elawad, 2011; Aucelio, de Souza, de Campos, Miekeley, \& Da Silva, 2007; Owrang, Mattsson, Olsson, \& Pedersen, 2004) and its concentration depends on the bearings inside the engine block (Yusaf et al., 2011; Owrang et al., 2004; Maduako, Ofunner, \& Ojinnaka, 1996). The concentration of iron in the recycled oil increased $(0.0082 \mathrm{ppm})$ when metakaolin was used. However, zeolite LTA and LSX reduced the iron concentration by $23.4 \%$ and $32.81 \%$ respectively. In case of copper, the removal efficiency of $38.10 \%$ with $19.04 \%$ and 47.61 and for zeolites LTA and LSX respectively. 


\subsection{Analysis of Oxidative Components}

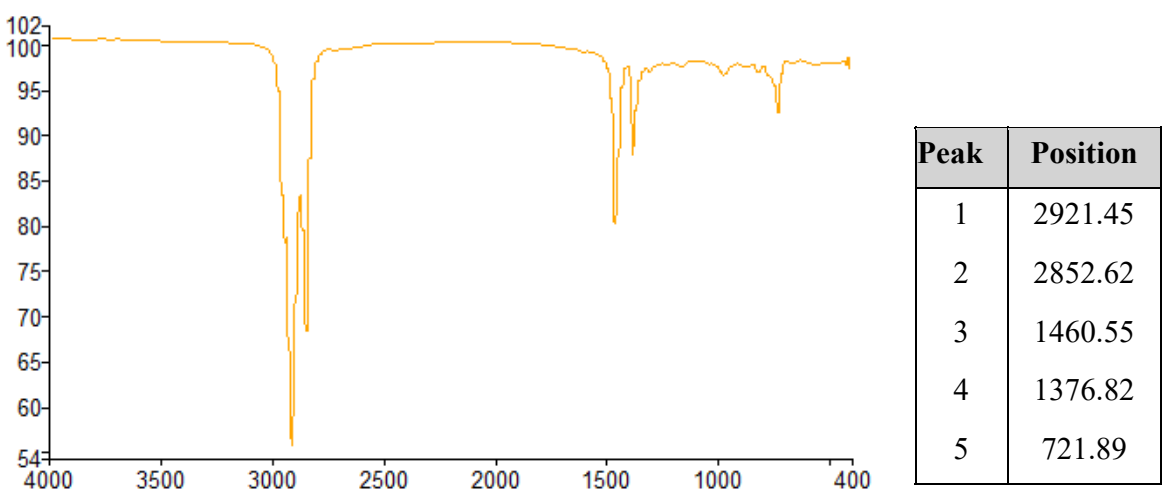

Figure 8. FTIR spectrum of virgin engine oil

The FT-IR results of the Virgin oil as shown in Figure 8 showed no peaks of oxidization which normally occurs around $1730 \mathrm{~cm}^{-1}$ and nitration which also occurs at $1630 \mathrm{~cm}^{-1}$. All these indicate a degradation of an engine oil. No bands were also observed at 3400 and 1150 and $960 \mathrm{~cm}^{-1}$ respectively indicating degradation of an engine oil due to sulfation, water and wear of additives products. The absence of all these bands really confirmed the virginity of this engine oil. The occurrence of oxidation in the lubricating engine oil was caused by the presence of oxygen in the cylinders of the engine block. This was at a particular pressure and temperature and can also be partitioned into two. That is oxidation at low and high temperatures. When low temperature oxidation occurs in an engine, it prompts the development of alkylhydroperoxides $\mathrm{ROOH}$, dialkylperoxides ROOR, alcohols $\mathrm{ROH}$, aldehydes $\mathrm{RCHO}$ and ketones $\mathrm{RR}^{\prime} \mathrm{C}=\mathrm{O}$. Likewise, cleavage of a dihydroperoxide also prompts the formation of diketones $\mathrm{RCO}(\mathrm{CH} 2)_{\mathrm{x}} \mathrm{COR}$, ketoaldehydes $\mathrm{RCO}(\mathrm{CH} 2)_{\mathrm{x}} \mathrm{CHO}$, and hydroxyketones $\mathrm{RCH}(\mathrm{OH})-(\mathrm{CH} 2)_{\mathrm{x}} \mathrm{COR}$. At elevated temperatures higher than $120^{\circ} \mathrm{C}$, the oxidation procedure is partitioned fundamentally into primary and secondary oxidation stages. At the primary oxidation stage, a start and proliferation of the radical chain reaction are the same as that initially talked about under low-temperature conditions, but however selectivity is decreased and reaction rates increased. At higher temperatures cleavage of hydroperoxides is the most imperative part. Carboxylic acids $(\mathrm{RCOOH})$ that was produced was one of the fundamental products delivered under these oxidation conditions. In the next step they reacted with alcohols $\mathrm{ROH}$ to produce esters (RCOOR). The end reaction continues through primary and secondary intermediary radicals at temperatures above $120^{\circ} \mathrm{C}$. These intermediary secondary radicals likewise reacted in a non-ending approach to produce primary and secondary alkoxy radicals (Kauffman, 1998; Aucelio et al., 2007). According to Aucelio et al. (2007) the secondary oxidation stage happens at higher temperatures where the viscosity of the mass medium increases as an after effect of the polycondensation of the broken oxygenated products formed at the primary oxidation stage. Further polycondensation and polymerization reactions of these high molecular weight intermediates lead to the formation of sludge (Yusaf, et al., 2011; Maduako et al., 1996). 

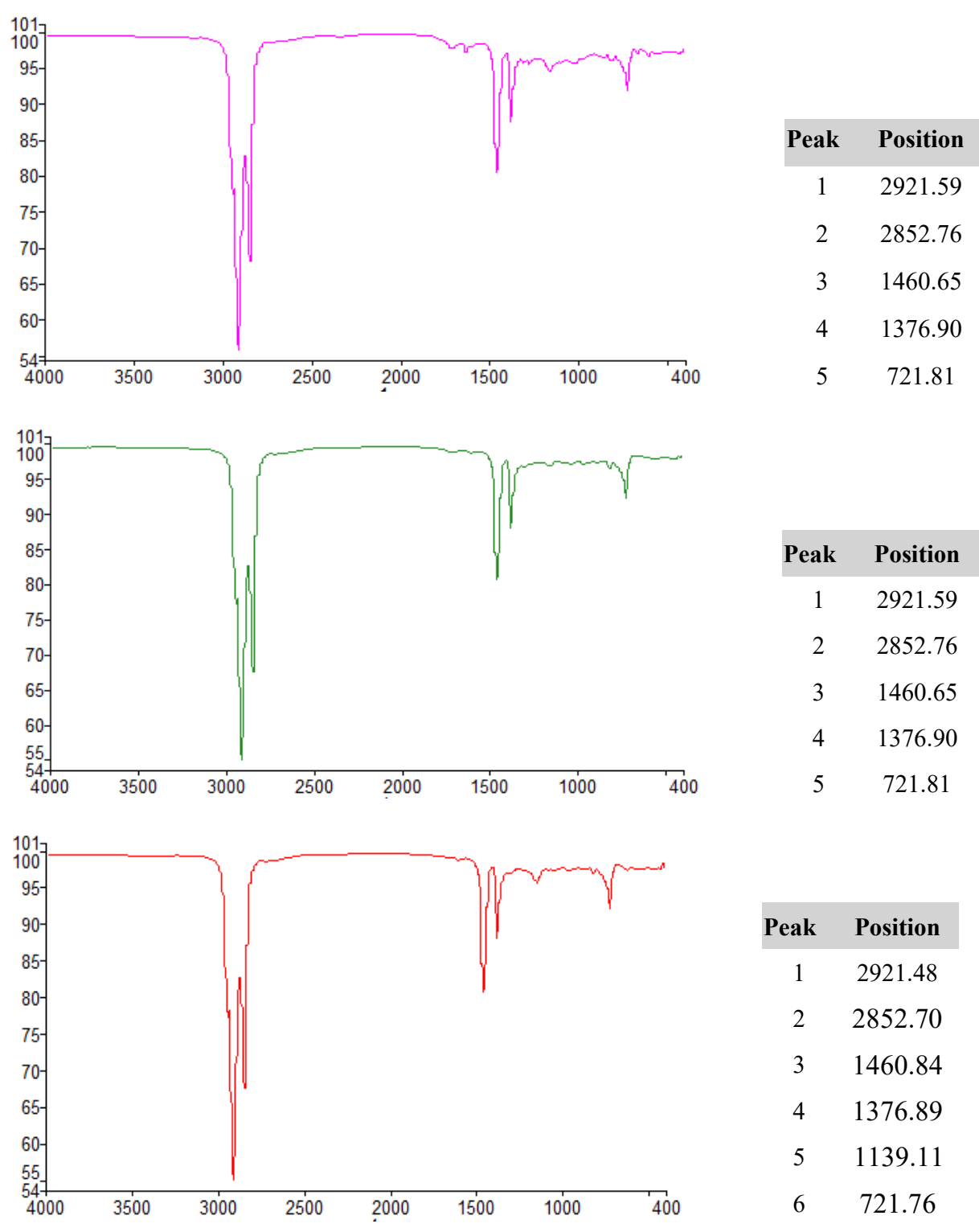

\begin{tabular}{cc} 
Peak & Position \\
\hline 1 & 2921.48 \\
2 & 2852.70 \\
3 & 1460.84 \\
4 & 1376.89 \\
5 & 1139.11 \\
6 & 721.76
\end{tabular}

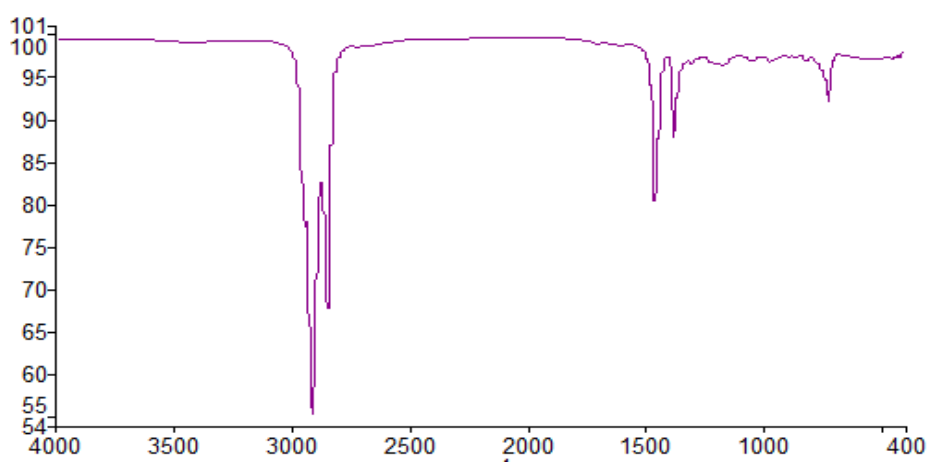

\begin{tabular}{cc}
\hline Peak & Position \\
\hline 1 & 2921.48 \\
2 & 2852.70 \\
3 & 1460.84 \\
4 & 1376.89 \\
5 & 1139.11 \\
6 & 721.76
\end{tabular}

Figure 11. FTIR spectrum of (a): used engine oil, (b): oil obtained after treating with acetic acid and metakaolin, (c): oil obtained after treating with acetic acid and zeolite LTA and (d): oil obtained after treating with acetic acid and zeolite LSX

The reaction of oxidation compounds in the lubricating oil test was analyzed by a Fourier Transform Infrared Spectrometer (Genesis II, Mattson, UK)). A spectral band at $1700-1750 \mathrm{~cm}^{-1}$ demonstrated the imminence of 
oxidation mixes, on account of the way that $(\mathrm{C}=\mathrm{O})$ bonds were firmly absorbed at this frequencies [36]. The spectrum of the used engine oil (Figure 9) showed medium new bands at 1704.82 and $1634.54 \mathrm{~cm}^{-1}$ indicating the presence of short chained compounds in carbonyl groups from esters, ketones or acids [37 - 39]. The formation of these compounds in the used engine oil was mainly due to the oxidation processes that occurred in the oil as it was in use. According to Diaz et al. (1996) and Riazi and Roomi (2001) used engine oil have bands at $1167.54 \mathrm{~cm}^{-1}$ which indicates the presence of peroxides compounds. Unsaturated additives had bands that were located at 703.55 $\mathrm{cm}^{-1}$ and $1603.13 \mathrm{~cm}^{-1}$. The presence of these bands 1235,1470 and $1356 \mathrm{~cm}^{-1}$ were due to the hydrocarbon compounds mixing with small chain lengths and $\mathrm{C}-\mathrm{H}$ vibrations within $\mathrm{C}-\mathrm{H}$ groups contained in the spent oil (Fox, Pawlak, \& Picken, 1991). The presence of aromatics and PAHs in the used oil were located by new bands that occurred at 850,810 and $1630 \mathrm{~cm}^{-1}$, which represented the hydrocarbons that were in the aromatic ring. There was also a degradation of the used oil as a result of absorption of water at the bands $900 \mathrm{~cm}^{-1}$ and fuel from the engine $1200 \mathrm{~cm}^{-1}$.

The results of the recycled oil followed by the addition of metakaolin, zeolite LTA and zeolite LSX showed no peaks of degradation as compared to that of the used oil (Figure, $10-12$ ). All the above results showed no oxidation, nitration and sulfation components. Hence the adsorbents Metakaolin, Zeolites A and LSX were all able to remove the degraded products from the spent engine oil.

\section{Conclusion}

The impact of recycling spent lubrication oil using different adsorbents such as metakaolin, zeolites A and LSX with Glacial acetic acid by mimicking the acid-clay percolation procedure, gave results with values that were comparable to that of the virgin lubrication oil. The outcome of this study demonstrated that the Acid-Metakaolinpermeation process gave lower quality recycled oil than that of Acid-Zeolites process. All the procedures additionally reduced the zinc content in the recycled oil with metakaolin and Zeolite A having higher expulsion. After the recycled process, the saturation compounds increased from $43 \%$ in the spent oil to a maximum yield of above $80 \%$. Clearly the Glacial acetic acid-zeolites percolation procedure was a decent system for the expulsion of pollutants from spent oil which upgrades the qualities of the spent oil similar to that of a quality base oil. This new Glacial acetic acid-zeolites recycling procedure have shown from this exploration work that, there would be a high probability of getting great quality base oils from spent lubricating engine oils. This will also be more practical and cheaper than the generation of the base oil from raw petroleum products, as the number of purification stages involved would be reduced.

\section{Acknowledgement}

The authors are grateful to Third World Academy of Science (TWAS) for providing research grant (\# 16-471 RG/PHYS/AF/AC_G.

\section{References}

ASTM (American Society for Testing and Materials) International. (2004). Standard test method for flash and fire points by Cleveland open cup tester; ASTM Standard D92. ASTM International: West Conshohocken, PA, USA.

ASTM International. (2004). Standard practice for calculating viscosity index from kinematic viscosity at $40{ }^{\circ} \mathrm{C}$ and $100{ }^{\circ} \mathrm{C}$; ASTM Standard D2270. ASTM International: West Conshohocken, PA, USA.

ASTM International. (2004). Standard test method for acid number of petroleum products by potentiometric titration; ASTM Standard D664. ASTM International: West Conshohocken, PA, USA.

ASTM International. (2004). Standard test method for density, relative density, or api gravity of crude petroleum and liquid petroleum products by hydrometer method; ASTM Standard D1298. ASTM International: West Conshohocken, PA, USA.

ASTM International. (2004). Standard test method for pour points; ASTM Standard D97. ASTM International: West Conshohocken, PA, USA.

ASTM International. (2004). Standard Test method for Rams bottom carbon residue of petroleum products; ASTM Standard D524. ASTM International: West Conshohocken, PA, USA.

ASTM International. (2004). Standard test method for refractive index and refractive dispersion of hydrocarbon liquids; ASTM Standard D1218. ASTM International: West Conshohocken, PA, USA.

ASTM International. (2004). Standard test method for water and sediment in crude oil by the centrifuge method (laboratory procedure); ASTM Standard D4007. ASTM International: West Conshohocken, PA, USA. 
Aucelio, R. Q., de Souza, R. M., de Campos, R. C., Miekeley, N., \& Da Silva, C. L. P. (2007). The Determination of Trace Metals in Lubricating Oils by Atomic Spectrometry. Spectrochimica Acta Part B Atomic Spectroscopy, 62, 952-961.

Boughton, B., \& Horvath, A. (2004). Environmental Assessment of Waste Oil Management Methods. Environmental Science and Technology, 38, 353-358.

Dang, C. S. (1997). Re-refining of Used Oils-A Review of Commercial Processes. Lubrication Science, 3, 445457.

Diaz, R. M., Bernardo, M. I., Fernandez, A. M., \& Folgueras, M. B. (1996). Prediction of the Viscosity of Lubricating Oil Blends at Any Temperature. Fuel, 75, 574-578.

Fox, M. F. (2007). Sustainability and environmental aspects of lubricants. In E. D. George, \& E. Totten, (Eds.), Handbook of Lubrication and Tribology. New York, NY: Taylor and Francis.

Fox, M. F., Pawlak, Z., \& Picken, D .J. (1991). Acid-Base Determination of Lubricating Oils. Tribology International, 24, 335-340.

Hamawand, I., Yusaf, T., \& Rafat, S. (2013). Recycling of Waste Engine Oils Using a New Washing Agent. Energies, 6(3), 1023-1049. http://doi.org/10.3390/en6021023

Kajdas, C. (2000). Major Pathways for Used Oil Disposal and Recycling, Part 1. Lubrication Science, 7(1), 6174. https://doi.org/10.1002/tt.3020070107

Kauffman, R. E. (1998). Rapid, Portable Voltammetric Techniques for Performing Antioxidant, Total Acid Number (TAN) and Total Base Number (TBN) Measurements. Tribotesting, 54, 39-46.

Kwakye-Awuah, B., Von-Kiti, E., Buamah, R., Nkrumah, I., \& Williams, C. (2014). Effect of Crystallization Time on the Hydrothermal Synthesis of Zeolites from Kaolin and Bauxite. International Journal of Scientific and Engineering Research, 5(2), 734-741.

Kwakye-Awuah, B., Von-Kiti, E., Nkrumah, I., \& Williams, C. (2013). Towards the Zeolitization of Bauxite: Thermal Behaviour of Gibbsite in High-Alumina-Ghanaian Bauxite. International Journal of Engineering Research and Technology, 2(10), 1290-1300.

Kwakye-Awuah, B., Von-Kiti, E., Nkrumah, I., Ikyereve, R. E., \& Williams, C. (2016). Parametric, Equilibrium, And Kinetic Study of the Removal of Salt Ions from Ghanaian Seawater by Adsorption onto Zeolite X. Desalination and Water Treatment, 57, 21654-21663.

Maduako, A. U. C., Ofunner, G. C., \& Ojinnaka, C. M. (1996). The Role of Metals in the Oxidative Degradation of Automotive Crankcase Oils. Tribology International, 29, 153-160.

Martins, J. P. (1997). The extraction-flocculation re-refining lubricating oil process using ternary organic solvents. Industrial and Engineering Chemistry Research, 36, 3854-3858.

Owrang, F., Mattsson, H., Olsson, J., \& Pedersen, J. (2004). Investigation of Oxidation of a Mineral and a Synthetic Engine Oil. Thermochimica. Acta, 413, 241-248.

Quang, D. V., Carriero, G., Schieppati, R., Comte, A., \& Andrews, J. W. (1974). Propane Purification of Used Lubricating Oils. Hydrocarbon Processing, 53, 129-131.

Reis, M. A. R., \& Jeronimo, M. S. (1998). Waste Lubricating Oil Re-Refining By Extraction-Flocculation. Industrial and Engineering Chemistry Research, 27, 1222-1228.

Riazi, M. R., \& Roomi, Y. A. (2001). Use of the Refractive Index in the Estimation of Thermophysical Properties of Hydrocarbons and Petroleum Mixtures. Industrial and Engineering Chemistry Research, 40, 1975-1984.

Rincon, J., Canizares, P., \& Garcia, M. T. (2005). Regeneration of Used Lubricating Oil by Polar Solvent Extraction. Industrial Engineering and Chemical Research, 44(12), 4373-4379.

Rincon, J., Canizares, P., \& Garcia, M. T. (2005). Waste Oil Recycling Using Mixtures of Polar Solvents. Industrial Engineering and Chemical Research, 44(20), 7854-7859.

Rincon, J., Canizares, P., Garcia, M. T., \& Gracia, I. (2003). Regeneration of Used Lubricant Oil by Propane Extraction Industrial and Engineering Chemistry Research, 42, 4867-4873.

Shakirullah, M., Ahmed, I., Saeed, M., Khan, M. A., Rehman, H., Ishaq, M., \& Shah, A. A. (2006). Environmentally Friendly Recovery and Characterization of Oil from Used Engine Lubricants. Journal of Chinese Chemical Society, 53, 335-342. 
Whisman, M. L., Reynolds, J. W., Goetzinger, J. W., Cotton, F. O., \& Brinkman, D. W. (1978). Re-Refining Makes Quality Oils. Hydrocarbon Processing, 57, 141-145.

Yusaf, T., Yusaf, B. F., \& Elawad, M. M. (2011). Crude Palm Oil Fuel for Diesel-Engines: Experimental and ANN Simulation Approaches. Energy, 36, 4871-4878.

\section{Copyrights}

Copyright for this article is retained by the author(s), with first publication rights granted to the journal.

This is an open-access article distributed under the terms and conditions of the Creative Commons Attribution license (http://creativecommons.org/licenses/by/4.0/). 